\title{
Opening Governance of the Academy of Management
}

\author{
Anne Tsui ${ }^{1}$
}

Received: 21 November 2015 / Accepted: 28 April 2016 /Published online: 28 July 2016

(C) Springer International Publishing 2016

I will focus my remarks on three topics:

1. How we can narrow the research practice gap and how bringing stakeholders of practice and policy into the AOM governance process.

2. Some suggestions for the business schools and how their governance processes could be opened to creating responsible management.

3. Reflect on how the younger and more international generation of scholars could pursue both rigorous and relevant research that leads them to career with purpose.

\section{AOM Governance for Good Science}

The Academy is an interesting organization. It does a great job of providing a platform for our members to share their research findings, exchange ideas, to social networking, and to meet prospective employers or employees. It publishes the leading journals in the field of management. It has the largest members of all management associations world wide, and its meetings have more members attending than many other professional associations. By most measures, AOM is a success story. Or is it? This is also an association with a high level of self-criticism of the problems in our research enterprise. Don Hambrick reminded us of our chase after theory is anomalous, compared to our sister disciplines. Bill Starbuck and Art Bedeian showed us our reviews are full of biases and random decisions. Herman Aguinis provided evidence that the most cited authors were rarely mentioned on non educational websites, suggesting that their ideas were unknown to the world of practice. Walsh and colleagues concluded that our

These remarks present a summary of Anne Tsui's contribution to a panel discussion organized by the Humanistic Management Network at the Academy of Management, August 9, 2015. Topic: Opening Governance of the AOM: The Academy between Rigor, Relevance and Irrelevance. The panelists were Michael Pirson (chair), Don Hambrick, Otto Scharmer, Anne Tsui, Hunter Lovins, and Henry Mintzberg (discussant)

Anne Tsui

Anne.Tsui@asu.edu 
research has focused more on performance outcomes than social outcomes, serving shareholders more than the employees and society. I complained about the lack of compassion in our research for stakeholders beyond shareholders. More recently, Roy Suddaby and Jerry Davis pointed out that our research has the appearance of science but the pressure to publish has led to systematic bias in the published papers. These problems threaten the integrity of science. Shouldn't the governance of AOM include the pursuit of good science? If a child is misbehaving, aren't the parents responsible for correction? If members of a volunteering organization (which AOM is) are engaging in behaviors inconsistent with the values of the profession, shouldn't the leadership of this association do something? In my humble view, AOM should include pursuit of good science in its governance.

Don Hambrick in his 1993 presidential speech asked the sobering question of "what if the Academy mattered?" Since then, many AOM presidents have spoken on the same topic, including Angelo DeNisi, Denise Rousseau, Tom Cummings, James Walsh (I might have left out quite a few), and myself. In most schools, there is only one criterion for tenure and promotion: the number of papers published in a pre defined set of journals. It does not matter what you study and whether your study has any relevance for practice. The research-practice gap is a familiar phrase and we are not even ashamed to admit that we don't care. This lack of concern for relevance has resulted in research that serves no one except those who write the papers and the schools they work for. Publications become the instrument for success by scholars and schools, not advancement of science or improvement of practice by business or other forms of organizations. The AOM governance has a "no advocacy" norm by refraining from issuing any policy statements or position papers on important management issues. The reason is that there are multiple voices or theories on each issue, and AOM cannot stand for any one voice. I am not sure nor agree with this reason since most sciences involve multiple voices, and alternative voices are desirable for progress in science. However, AOM does care as expressed in its vision "We inspire and enable a better world through our scholarship and teaching about management and organization." I am not sure that we have lived up to this vision, given that we currently don't seem to care whether our scholarship is useful for practice, and as an association, we have not yet done anything about research practices that are steering us away from good science.

So, my first conclusion is that AOM should open its governance to promote good science among its members. We must help our members to be responsible scientists and caring citizens.

\section{Business School Governance for Responsible Management}

We are all part of the Academy and collectively we can do something to change science for the better. What about the schools where we work? What are our roles and responsibilities? I have good news for you. In most business schools, especially those in the democratic states, we follow the model of faculty governance. We, the faculty, can decide what the school should value. Recently, I had a conversation with the dean of a very prestigious business school. She said that she has no power to make any change. Everything has to be done through faculty committees. If we want our research to matter to society, then we need to change our tenure and promotion criteria to support this value. If we want our students to be responsible leaders who work to create value for all stakeholders and not only shareholders, we have to change the curriculum and the content of what we teach. There is convincing evidence that our exclusive focus on shareholder values has led to harm to society 
in many areas, including employee stress, resource depletion, air and water pollution, global warming, irresponsible investments and financial crisis, producing major hardship for small investors and job losses. Business schools need to be more engaged with and concerned about a variety of stakeholders including employees, customers, suppliers, and citizens in the community. We may have to open the governance of the school to include some of these stakeholders and to teach our students to be responsible leaders and managers. I realize that I am not saying anything new or surprising here. So, let me move on to the third topic, how younger and international scholars can pursue a meaningful career in science. I believe this is another issue that ideally should fall into the governance domain of AOM.

\section{AOM Governance for a Meaningful Career in Science for the new Generation of Scholars}

The major growth in the membership of AOM has been the entry of international scholars. Currently, almost $50 \%$ of AOM members are from outside the United States and the majority of them are from Asia and Europe. Almost a third are student members. This younger generation of scholars is the future of our academy, broadly define, and the future leadership of AOM. Sadly, in my view, most of them are taught to write papers rather than pursue science. They come to the academy to learn how to succeed in their career rather than how to become the next Albert Einstein, Don Hambrick, Jeff Pfeffer, or Henry Mintzberg. Their aspiration is getting tenure, getting published rather than having major discoveries or developing an important theory. Most doctoral programs do not inspire them to become important scientists but train them to be paper production workers. This does not sound like a very meaningful career. I am surprised that not more of them leave this career as Bill Glick said they should in his 2007 JOB paper that created a ripple, but did not develop a storm, sadly I should say. It appears that most young scholars have succumbed to this reality and believe that their career aspiration is to publish in AMJ, ASQ, JAP, SMJ, or OS. What they study does not matter. I believe both AOM as their professional home and business schools as their employers have a responsibility to put these talents to better use than to produce papers that have no social or even intellectual value.

In conclusion, the AOM governance should include the career development of young scientist as valued intellectual resource for our fields and as our future great contributors to knowledge and practice through engaging in research that is both rigorous and relevant. By so doing, they make this world a better place and they find their career to be filled with meaning and purpose. This is the scientific career that they deserve.

The AOM leadership would be truly serving its members if it opens its governance to include three important agendas that I have discussed: promote good science, close the research-practice gap through research and teaching on responsible management, and develop young talents for a meaningful scientific career. Thank you. 